\title{
Demography, Growth, and Global Income Inequality
}

\author{
WARD ROUGOOR ${ }^{\mathrm{a}}$ and CHARLES VAN MARREWIJK ${ }^{\mathrm{b}, \mathrm{c},{ }^{*}}$ \\ ${ }^{a}$ SEO Economic Research, Amsterdam, The Netherlands \\ ${ }^{\mathrm{b}}$ Xi'an Jiaotong - Liverpool University, China \\ ${ }^{\mathrm{c}}$ Utrecht University, The Netherlands
}

\begin{abstract}
Summary. - Global income inequality has been declining for several decades. We argue that global income inequality will reach its lowest level around 2027 and then will rise again. This development is the result of both economic and demographic forces. By combining economic projections with demographic developments and by using GDP per worker instead of GDP per capita in projecting income levels we emphasize the role of demographics in income inequality. Especially in the long run (after 2030), differences in population growth and population structure between countries in different stages of development are shown to increase global income inequality.

(c) 2015 Elsevier Ltd. All rights reserved.
\end{abstract}

Key words - income inequality, Gini coefficient, age distribution, population, world distribution of income, poverty

\section{INTRODUCTION}

The past trends in (global) income inequality are well documented. But what trends can be expected in the future? We develop several global growth scenario's in order to project changes in income inequality in the next four decades.

The first industrial revolution brought with it a period of at least a 100 years of increasing income inequality in the world (Bourguignon \& Morrisson, 2002). After first stabilizing halfway through the 20th century, a trend of global inequality reduction has been set in after the $1960 \mathrm{~s}$, one which continues to this day (Sala-i-Martin, 2006). The demographic and economic growth forces underlying these developments are analyzed in Firebaugh and Goesling (2004). A natural question to ask is, what will happen in the coming decades? We argue that the answer combines developments in both Africa and Asia. We have seen unstable growth in Africa, which might actually have continued diverging away from OECD countries. Asia, in contrast, has been the driving force behind the recent income convergence. Many Asian countries, among which populous nations like China and India, are rapidly developing. They are simultaneously catching up with OECD countries and pulling away from other developing countries, resulting in two opposing forces that will shape the trend in global income inequality in the near future.

We develop several global growth scenario's up to 2050 in order to project global income inequality in the next 40 years. Economic growth, driven by productivity increases, naturally plays a large part in this process, but given the long time horizon, demographic developments do so as well. For example, the population of Africa is projected to double in the coming four decades. At the same time Asian countries profit from a beneficial age structure, as many advanced countries have over the past decades. These countries are now starting to struggle with aging populations and fertility rates below replacement levels. All these developments directly (through economic growth) or indirectly (through the share of working age population) impact on global inequality. These developments are the central theme in this paper, which is the first paper to include both future population growth and population dynamics (age structure) by using GDP per worker as the underlying variable for future growth projections. This combined projection allows us to differentiate between economic and demographic effects on income inequality.

Section 2 gives an overview of the main findings of previous research regarding growth, inequality, demography, the interplay between them. Section 3 describes the data and methodology. Section 4 presents the results on global income inequality. Section 5 introduces a number of alternative scenario's as a robustness check for our main findings. Section 6 discusses recent literature and data on changes in within-country income inequality. The final section summarizes the most important conclusions.

\section{LITERATURE REVIEW}

Many interactions exist between economic and demographic variables. Future income inequality will be shaped by economic growth differences between countries as well as differences in population growth and the relative size of the working age population in each country.

\section{(a) Inequality in the past}

The academic discussion on economic growth and income inequality has, for obvious reasons, mainly focussed on the past (Bourguignon \& Morrisson, 2002; Brat, 1995; Jones, 1998; Milanovic \& Yitzhaki, 2002; Park, 2001; Sala-i-Martin, 2006; Schultz, 1998). Rising global income inequality in the past two centuries has been the rule rather than the exception, driven by the strong and continuous growth of a small number of (OECD) countries after the industrial revolution. This resulted in a twin-peak world income distribution, characterized by a large number of people (countries) with a low income level and a smaller group of

\footnotetext{
* This paper was presented at the Dutch Economists Society Conference at the Dutch Central Bank, 18 October 2013. We are grateful to three anonymous referees and the conference participants for detailed comments and suggestions. Any remaining errors are, of course, our own. Final revision accepted: May 19, 2015.
} 
people (countries) with a high income level, and not much in between. Milanovic and Yitzhaki (2002) therefore conclude that the world as a whole did not have a middle class.

Firebaugh and Goesling (2004) distinguish between "equalizing" and "disequalizing" factors. From the 1970s onward equalizing factors proved stronger than disequalizing factors and a trend toward lower global inequality started. The authors discuss these factors for the final two decades of the twentieth century. Major equalizing factors were the faster-than-world-average income growth in (i) China and (ii) South Asia, combined with (iii) a slower-thanworld-average population growth in the Western offshoots. Major disequalizing factors were (i) slower-than-worldaverage income growth in sub-Saharan Africa, combined with (ii) a faster-than-world-average population growth in that region, and (iii) faster-than-world-average income growth in the Western offshoots. Firebaugh (2003) provides a more comprehensive analysis of the forces discussed above in relationship to globalization. We discuss similar forces to explain the future reversal of the trend of declining global income inequality in Subsection 4(b).

Amsden (2001) provides an overview of the dynamics underlying newfound growth in developing countries and the different approaches taken by developing countries. She distinguishes between countries coined "independents" and "integrationists". The independents include China, India, Korea, and Taiwan, the integrationists include Argentina, Brazil, Chile, Mexico, and Turkey. The independents have chosen a growth strategy in which the build-up of national firms and R\&D expenditures are central. Amsden refers to this as the "make" technology decision. The integrationists rely more heavily on foreign direct investment and technology transfers, the "buy" technology decision. The strategic choice has influenced the economies of the developing countries over the past 30 years and will likely remain relevant for between- as well as within-country inequality in the future.

When using a decomposable inequality measure, such as the Mean Log Deviation (MLD) or the Theil index, the global inequality decline from 1979 to 1996 can be shown to be caused by a decrease of between-country inequality despite a rise of within-country inequality (Sala-i-Martin, 2006). It is thus possible that the overall convergence is mainly caused by income growth in the high-income quintiles of poor countries, leaving the income of the poorest people virtually unchanged. Ravallion (2001) finds that for two household surveys in the 1980s and 1990s held in 47 developing countries an increase in average household income typically came with a decrease in poverty. However, in just over half the cases where average household income increased this coincided with an increase in within-country inequality. For those cases where inequality increased a lower median rate of poverty reduction $(1.3 \%$ versus $9.6 \%)$ was observed.

Edward (2006) provides estimates detailing that about $46 \%$ of the increase in consumption during 1993-2001 benefitted the world's highest income decile. In China growth mainly benefitted the middleclass. About $25 \%$ of global growth can be attributed to China as a whole. As Edward notes (2006, p. 1677): "The poorest half of the world's population received less than one-tenth of the global growth of the 1990s." The poorest people have thus in general been able to benefit from the convergence trend resulting in a decline in absolute poverty numbers (Dollar, 2005). Nevertheless, the poorest benefit only to a limited extent and these benefits go predominantly to the poor people in China.

\section{(b) Similar research}

It is quite common to investigate future income growth trends. Large investment banks (Buiter \& Rahbari, 2011; Hawksworth \& Cookson, 2008; Wilson \& Purushothaman, 2003), as well as research institutes (Dadush \& Stancil, 2010; Fouré, Bénassy-Quéré, \& Fantagné, 2010; Poncet, 2006) have presented growth predictions up to the year 2050. This literature is, however, silent on the possible implications for global income inequality. Understandably, results are not completely uniform. This is in part due to differences in focus and/or data and partly because the time frame extrapolates minor variations in assumptions. Nonetheless, there is a general consensus on which countries will grow fast over the next 40 years: Asian countries. Eight out of the top ten growers identified by Buiter and Rahbari (2011) are Asian countries. In Hawksworth and Cookson (2008) the only nonAsian countries among the top 10 are Nigeria and Egypt. Besides Asia, Dadush and Stancil (2010) also have high expectations for Latin America and some African countries: Ethiopia, Kenya, Nigeria, and Ghana.

With regard to inequality a natural question to pose is: what effect will growth differences have on future global inequality? Although the question was posed by Sala-i-Martin (2002, 2006 ) it was given only minor further attention in these papers and is only briefly modeled with some extreme assumptions (such as no growth during 1998-2050 for many African countries). The growth predictions mentioned above are also only marginally useful in such an exercise, as the models are data intensive such that many countries will have to be excluded. Furthermore, there is a bias in the countries chosen to evaluate, namely the likely winners. We return to this issue in Section 6.

A study analyzing future income inequality trends requires a different approach, namely one that allows for inclusion of virtually all countries of the world, as well as the possibility to evaluate several scenarios, thus acknowledging that a lot can happen in 40 years time. Quah (1993) tries to tackle a similar question using a probability model, which calculates the probability of a country moving to the next income threshold. It proves to be an elegant but rather abstract approach. Countries converge toward extremes (either rich or poor), but the mechanics behind this outcome remain difficult to grasp. Jones (1998) initially holds on to neoclassical theory and assumes convergence toward "predetermined" income levels but also includes a long-run probability model in extension of the work done by Quah. He concludes that there has been a tendency to move up in the income distribution, which is likely to continue due to developments in China and India. In retrospect, this has indeed been the case.

To the best of our knowledge there are only two other articles analyzing future poverty and global inequality. Hung and Kucinskas (2011) focus attention on the impact of China and India only for the period 1980-2005. The last part of the paper also provides a simple projection into the future (until 2030) by holding growth rates and population shares for all countries constant at the 1980-2005 level, combined with a scenario in which this also holds for China and India and another scenario in which the growth rate for these two countries is halved. Both scenario's focus attention on the role of China and India and depict an eventual increase in income inequality in the future once China or India's average income exceeds the world average.

A more sophisticated projection is made by Hillebrand (2008) who uses Bhalla's (2002) simple accounting procedure 
to estimate income inequality in 2050 using two different growth scenarios. Hillebrand's focus is on the implications of growth for poverty rates (headcount). He estimates a continuing decline in global income inequality from 2005 to 2050 in his base case (the "Market First" scenario). Only by assuming drastically lower growth rates for a large group of developing countries (Sub-Saharan Africa, the Middle East, and Latin America; the "Trend Growth" scenario) does he find a reversal of this trend sometime in the future. In contrast, our analysis finds an imminent reversal to rising global income inequality measures, somewhere around the mid 2020s, for a range of different and plausible scenarios without the need to artificially impose a decline in growth rates for certain parts of the world. The main reason for these diverging outcomes is a different treatment of demographic factors and more attention for the age distribution of the population, with a focus on the working age population relative to the total population. The methodology discussed in Section 3 allows for an analysis of the dynamics behind the relative welfare shifts found whereas Hillebrand "jumps" to 2050 without describing the process in between. ${ }^{1}$ This is where this paper fits in and contributes to the existing literature.

\section{(c) Demography and economic growth}

The premise of this paper is that the combination of economic and demographic developments (both of which differ greatly between countries) might result in a comeback of rising income inequality somewhere in the next few decades. The initial industrial revolution has greatly increased global inequality, a new wave of industrializing countries might do the same, once the pull-away (from less fortunate countries) factor starts to outweigh the catch-up (to OECD countries) factor. This will likely be enhanced by demographic developments. Most of the world's population growth in the next few decades will come from high fertility, low-income countries.

The African continent is expected to grow from just over 1 billion inhabitants now, to more than 2.2 billion in 2050 (United Nations Population Department, 2011). Many of these people are born into poverty. Demographic developments thus play a vital role in predicting the future world distribution of income. Naturally, demographic developments affect not only in how many slices the "income pie" has to be cut but also interact with economic developments. Brander and Dowrick (1994), for example, use cross-country panel data to examine the effects of fertility and population growth on economic growth and find that fertility and per capita income simultaneously influence each other. As per capita income rises, fertility tends to decline. At the same time, as fertility declines, investment effects enable rapid increases in per capita income.

Brander and Dowrick (1994) also note that a sudden fertility decline can have an important impact on the relative size of the working age population in the medium run, thus enabling a period of rapid economic growth. Bloom, Canning, and Malayney (1999) show this mechanism at work in explaining the East-Asian miracle. They pinpoint South-East Asia as the next region to experience a big growth spurt. On the other hand, they emphasize that demographic transition is a necessary rather than a sufficient condition for economic growth acceleration; South-Asia, for example, seemed unable to fully profit from its positive demographic developments. Williamson (1998) concludes on this matter: "Demographic forces need not always have a profound impact on growth or distribution. They depend on the historical time and place. For it to matter, the demographic shocks must be big, they must be mostly exogenous with respect to the growth itself, and they must translate into changes in the age distribution." Firebaugh and Goesling (2004) show that for the world as a whole during the 1980s and 1990s the changes in worker ratios have been a disequalizing factor. This is predominantly the result of a lagging demographic transition in developing countries, with China as a notable exception. This indirect effect of population growth was nevertheless trumped by the larger force of strong income growth in countries with a large population size.

Similarly, Bloom and Sachs (1998) depict the lack of fertility slow-down, and thus the lack of demographic transition, in Africa as one of the main reasons why poverty is still plaguing the continent. Instead of a traditional demographic transition this has thus far only led to a high share of young people in the population. Only about $50 \%$ of the total population is of working age whereas other continents sometimes come close to $70 \%$. Needless to say, this has had a profound impact on development and is likely to be one of the reasons why Asia has been outgrowing Africa for the past few decades. Lindh and Malmberg (2007) look into the future, to 2050. They make demography-based predictions of economic growth and find a general pattern of already advanced countries experiencing stagnating growth whereas developing countries take off.

Sub-Saharan Africa is expected to be the only exception to this rule, mainly due to continuing high fertility and the AIDS epidemic. The validity and consequences of these observations is analyzed next.

\section{METHODOLOGY}

Using GDP data for 176 countries, combined with demographic information on the size of the working population, and country level information on income quintiles we construct a basic income growth scenario up to 2050. The next section will analyze the consequences for global income inequality measures.

\section{(a) Economic variables}

Using the UNU-WIDER database (2008) in combination with the Penn World Tables (2011) provides income quintile information for 137 countries divided over six continents (Africa, Asia, Latin America, Europe, North America, and Oceania), together accounting for about $96 \%$ of the world population. Using this information, income quintiles per continent in 2009 are calculated, based on the population, income, and quintile information for the countries for which this information is available. For the 39 remaining countries with missing income quintile information, together accounting for the remaining $4 \%$ of the world population, these respective continent-wide income quintiles are used. We keep the quintile distributions constant for the projection period for all countries. Section 6 provides a discussion of changes of within-country income inequality at the country level. Appendix A provides an overview of all included countries.

Regarding our income projections, we proceed in four steps. Step 1. We determine a country's total real GDP (in 2005 international dollars) in the period 1990-2009 from the Heston, Summers, and Aten (2011) data base.

Step 2. We use the UN (2011) population information to determine GDP per worker for each country in this period. We use regressions of these data from the period 1990 to 2009 at the country level as the basis for our GDP per worker growth projections. Figure 1 shows the distribution 


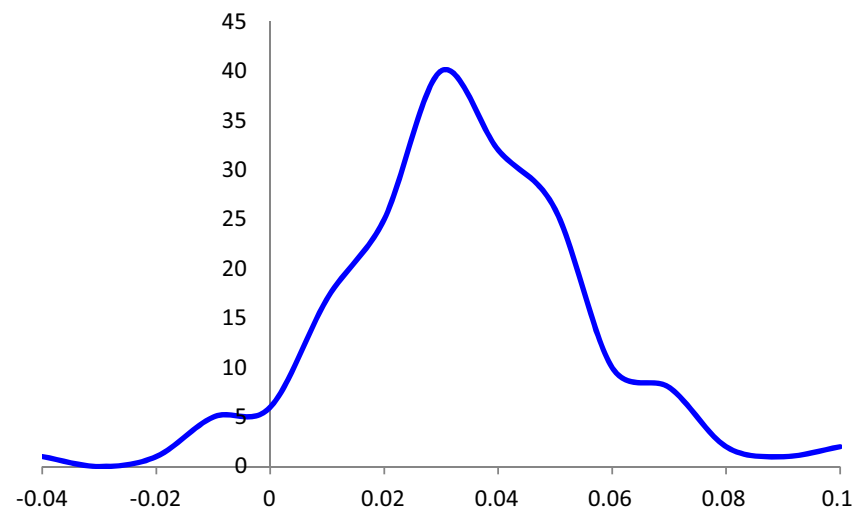

Figure 1. Distribution of GDP per worker growth rates; per country 19902009. Source: Authors' calculations based on United Nations (2008), United Nations Population Department (2011) and Heston et al. (2011). World average is $3.79 \%$ per year.

of the GDP per worker growth rates for individual countries. The country median growth rate is 3.83 , which is close to the world average growth rate (using world GDP per worker data) of 3.79. On both sides of the distribution is a number of smaller countries with an exceptional development of GDP per worker growth rates. These are typically due to oil discoveries or (recovery from) wars. We mitigate the impact of estimated growth rates for future projections in the base scenario in three ways:

- Some outliers are eliminated by imposing the second-lowest growth rate for the country with the lowest growth rate (Congo, Dem. Rep.) and the third-largest growth rate for the two countries with the highest growth rates (Eritrea and Bosnia Herzegovina).

- Since the performance of countries that currently grow fast is likely to decline and for countries that currently grow slowly is likely to improve, continent-wide average growth rates (using continent GDP per worker data) are calculated on which a gradual reversal to the continent-average per country is imposed, namely linearly over a period of 40 years. ${ }^{2}$ If, hypothetically, a country's growth rate in the period 1990-2009 is $8 \%$ per worker and this country's continent-wide growth rate is $2 \%$, then the imposed growth rate per worker is $8 \%$ in 2010 , declining to $7.85 \%$ in 2011 , to $7.70 \%$ in 2012, and so on.

- A minimum and maximum GDP per worker relative to the world average GDP per worker level in a given year is imposed. Figure 2 illustrates that both the minimum and the maximum relative to the world average fluctuated over time in the period 1970-2009 without a clear trend. To avoid extremes going beyond these historical limits, bounds of $1.5 \%$ of the world average as a minimum and 10 times the world average as a maximum are imposed. These are close to the observed extremes. ${ }^{3}$ Step 3. We use the UN (2011) working population projections for each country up to 2050 in combination with our GDP per worker projections to determine each country's total GDP in every year for the period 2010-15. A country's total income level is thus determined by the size of its working population in combination with the average projected productivity of the individual workers.

Step 4. To determine the income level of different groups within each country, which of course includes the whole population and not just the working population, we now determine the average income level for each quintile group

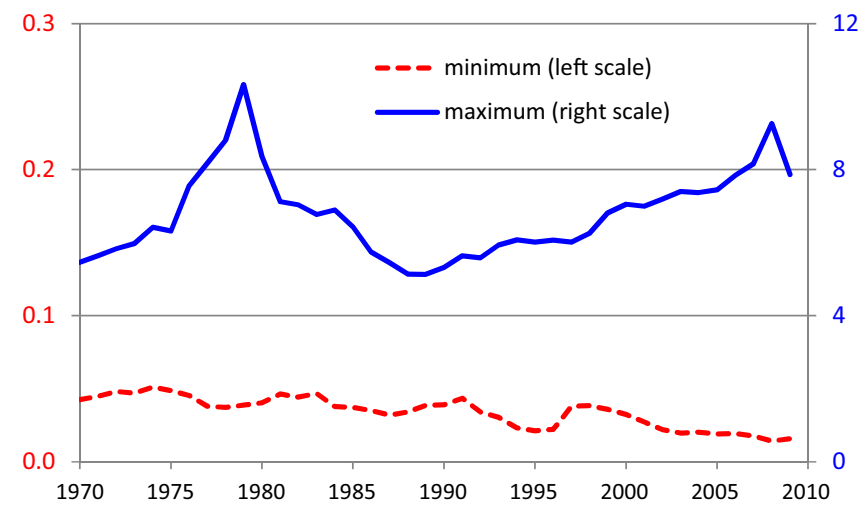

Figure 2. Minimum and maximum GDP per worker relative to world average, 1970-2009. Source: Authors' calculations based on United Nations (2008), United Nations Population Department (2011) and Heston et al. (2011).

in each country in every year by combining the quintile information described above with the total GDP projection and the total population projection provided by UN (2011) up to 2050. The next section discusses the consequences of these projections for global income inequality.

\section{(b) Demographic variables}

The United Nations Population Department (2011) provides detailed predictions regarding population developments per country up to the year 2100 , including the share of the young population, the working population, and the old population. Indeed, this information is already indispensable to determine the economic variables as discussed in Subsection 3(a). To this end we use the medium variant for our purposes, where we take the predicted GDP per worker for a particular country as explained above and multiply by the working population to get a prediction for total GDP. We then calculate the respective quintile shares for the entire population by dividing the relevant income fraction by the fraction of the total population to get an estimate of the income levels for the different fractions of the population in that country. ${ }^{4}$

Figure 3 gives an indication of the importance of using GDP per worker instead of GDP per capita for this exercise. Over the time period 1990-2009, Europe, North America, and Oceania all enjoyed high shares of working age population and, not completely unrelated, high per capita growth rates. These continents were the first to enter into the demographic transition and have enjoyed its benefits over the past few decades. Rising life expectancy combined with rapidly falling fertility rates in Latin America and Asia since the 1970s have resulted in a $13-14 \%$ point increase of the working age population in 40 years time. Working age population will peak in Asia and Latin America during 2015-30, approximately 15 years after the advanced countries in Europe, North America, and Oceania.

Figure 3 makes two important points with regard to Africa. First, Africa lags behind other continents in its demographic transition: the share of the working age population only started to increase in the 1990s. Second, continuing high fertility rates slow down the growth of the share of the working age population. Whereas Asia's share of the working age population rose $13 \%$ points in 40 years, Africa's is expected to increase only $11 \%$ points over 60 years. As a direct result of these developments, the United Nations Population Department (2011) predicts the working age share to peak in 


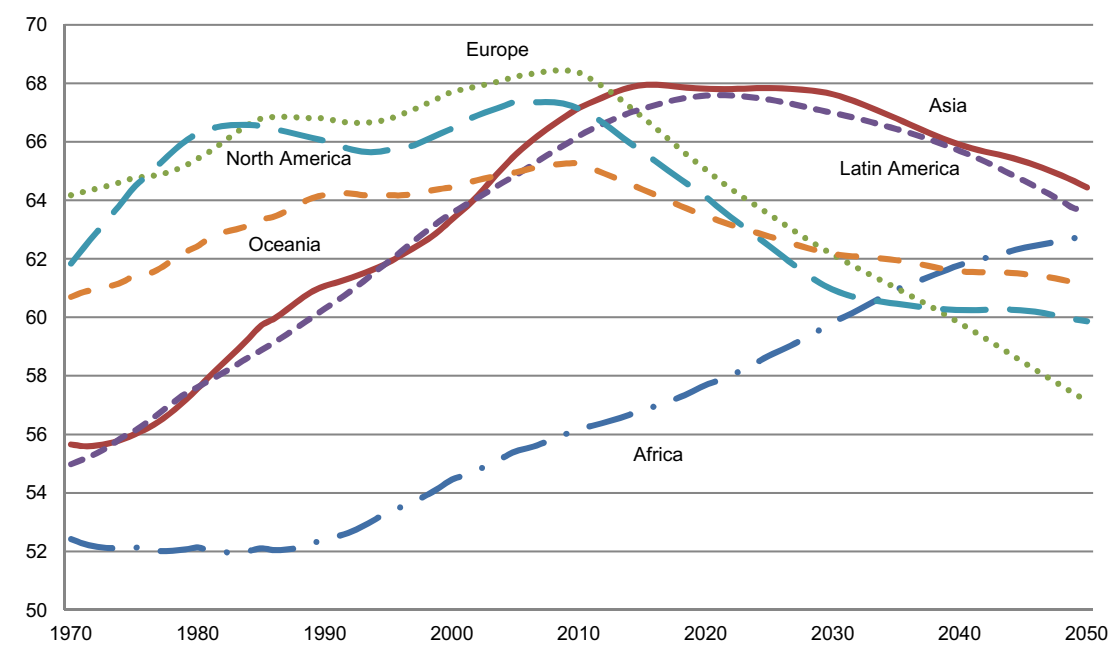

Figure 3. Working age population, \% of total population, 1970-2050. Data source: United Nations Population Department (2011).

2075 at just over $64 \%$, significantly lower than the share of Asia or Europe at their respective peaks.

Note that international migration flows are important (see United Nations, 2009) and also play a role in the UN's population projections. As such, the expected flows over longer time periods are incorporated in our analysis. More specifically, the largest net immigration countries are expected to be USA, Italy, and Canada, while the largest net emigration countries are expected to be China, India, Pakistan, the Philippines, and Bangladesh (UN, 2011). Migratory patterns may alter the demographic structure and thus influence GDP growth. Our work is contingent on the demographic structure projected by the UN and thus takes into account that migration patterns may influence GDP growth by altering, for example, the size of the working age population. Most importantly in this respect is the gap (about 11\% points) in working age population between Asia and Africa. Over time the gap will diminish, but most African countries will be faced with less favorable demographic developments compared to their Asian counterparts in the coming decades. When migration is large relative to the size of the population it may also directly affect average GDP per worker or the level of inequality in a country. This will likely only occur in a select number of small countries with limited impact on global inequality patterns. Additionally, migration patterns appear to remain relatively stable. All regions that were net-receivers of migration during 1990-2009 are expected to still be net-receivers during 2040-50 (UN, 2011). The GDP per capita estimations for 1990-2009 thus already include a large part of the effect that migration may have on productivity

\section{(c) Base scenario projections}

Table 1 provides a summary of the main economic and demographic variables for the base scenario at 10 year intervals. Total world income increases by a factor of 6.7 over the 2010-50 period, both because of a larger population (by a factor of 1.4) and because of higher income per capita (by a factor of 5.0). Although substantial, this is significantly lower than the 13.2 fold actual increase in world income over the comparable period 1970-2009, the result of a 1.9 fold increase in population and a 7.1 fold increase in income per capita.

Asia's income share is expected to rise by about $15 \%$ points, that of Africa and Oceania by less than $1 \%$ point. The income shares of Latin America and North America decline by about
$4 \%$ points, that of Europe by about $9 \%$ points. These changes are, of course, the result of changes in the total population, the working population, and production per worker. Total population more than doubles in Africa, compared to about $30 \%$ for most of the rest of the world, except for Europe, which has a stagnant population. ${ }^{5}$ Africa is the only continent where the share of the working population increases by $6.6 \%$ points. In the other continents it declines, ranging from $1.5 \%$ points for Latin America to $11.2 \%$ points for Europe. Average GDP per capita is expected to increase 5.0-fold from 2010 to 2050 , virtually the same as the 5.1-fold increase in average GDP per worker. This reflects the fact that for the world as a whole the rise in the working age population is almost the same as the rise in total population, namely $31 \%$ and $35 \%$, respectively. The rapid increase in Africa's population and its substantial rise in the share of working age population thus almost perfectly compensates for the decline of this share on the other continents.

Figure 4 illustrates the increase in average GDP per worker at the continent level using a log scale (such that the slope of a line reflects its growth rate). As we see (and is further detailed in Table 1e) Oceania is projected to catch up to the world leader North America in terms of GDP per worker by about 2050. Europe is expected to close this gap somewhat. The largest relative increase comes, however, from Asia, which is expected to overtake Latin America in terms of GDP per worker by about 2032. The relative losers are Africa and Latin America, which both see the gap of GDP per worker rise instead of fall. We discuss the implications of these differences for global income inequality in the next section.

\section{TRENDS IN GLOBAL INCOME INEQUALITY}

As we discuss below, the base scenario projects a reversal of the current trend toward lower global income inequality. The turning point is expected to be reached around 2027. Rising income levels in many Asian economies and continuing high population growth rates in Sub Sahara Africa are the most important drivers behind this trend reversal.

\section{(a) Lorenz curve and Gini-coefficient}

Figure 5 summarizes the outcome for the evolution of global income inequality, measured using the Gini coefficient, for the period 1990-2050. The first decade (1990-2000) shows a minor 
Table 1. Summary of base scenario projections

\begin{tabular}{|c|c|c|c|c|c|}
\hline Year & 2010 & 2020 & 2030 & 2040 & 2050 \\
\hline \multicolumn{6}{|l|}{$1 a G D P$} \\
\hline World, billion & 79,510 & 133,785 & 220,331 & 347,933 & 534,401 \\
\hline \multicolumn{6}{|c|}{ Continent, $\%$ of world total GDP } \\
\hline Africa & 4.4 & 4.5 & 4.7 & 5.0 & 5.1 \\
\hline Asia & 39.7 & 45.5 & 50.5 & 53.2 & 55.0 \\
\hline Latin America & 9.2 & 8.5 & 7.5 & 6.7 & 5.8 \\
\hline Europe & 24.9 & 21.6 & 18.9 & 17.2 & 16.0 \\
\hline North America & 20.2 & 18.3 & 16.6 & 16.1 & 16.1 \\
\hline Oceania & 1.6 & 1.6 & 1.7 & 1.8 & 2.0 \\
\hline \multicolumn{6}{|c|}{$1 b$ Total population, million } \\
\hline Africa & 1,021 & 1,276 & 1,560 & 1,867 & 2,189 \\
\hline Asia & 4,064 & 4,458 & 4,756 & 4,947 & 5,028 \\
\hline Latin America & 588 & 650 & 700 & 733 & 749 \\
\hline Europe & 722 & 728 & 726 & 717 & 705 \\
\hline North America & 344 & 374 & 402 & 425 & 447 \\
\hline Oceania & 36 & 41 & 46 & 50 & 54 \\
\hline \multicolumn{6}{|c|}{ 1c Working population, $\%$ of continent total } \\
\hline Africa & 56.2 & 57.7 & 59.8 & 61.8 & 62.8 \\
\hline Asia & 67.3 & 68.0 & 67.8 & 66.1 & 64.6 \\
\hline Latin America & 65.2 & 67.0 & 66.7 & 65.7 & 63.7 \\
\hline Europe & 68.4 & 65.0 & 62.1 & 59.8 & 57.1 \\
\hline North America & 67.1 & 64.1 & 60.9 & 60.2 & 59.9 \\
\hline Oceania & 65.3 & 63.5 & 62.2 & 61.6 & 61.1 \\
\hline \multicolumn{6}{|c|}{$1 d$ GDP per capita } \\
\hline World & 11,737 & 17,771 & 26,908 & 39,814 & 58,268 \\
\hline \multicolumn{6}{|c|}{ Continent, relative to North America (\%) } \\
\hline Africa & 7.4 & 7.3 & 7.4 & 7.1 & 6.5 \\
\hline Asia & 16.7 & 20.9 & 25.7 & 28.3 & 30.4 \\
\hline Latin America & 26.8 & 26.8 & 26.1 & 24.0 & 21.6 \\
\hline Europe & 58.8 & 60.7 & 63.0 & 63.0 & 62.9 \\
\hline Oceania & 75.6 & 82.6 & 90.8 & 96.9 & 102.5 \\
\hline \multicolumn{6}{|c|}{ 1e GDP per worker } \\
\hline World & 17,903 & 27,069 & 41,199 & 61,923 & 92,097 \\
\hline \multicolumn{6}{|c|}{ Continent, relative to North America (\%) } \\
\hline Africa & 8.8 & 8.1 & 7.5 & 6.9 & 6.2 \\
\hline Asia & 16.6 & 19.7 & 23.1 & 25.8 & 28.1 \\
\hline Latin America & 27.6 & 25.6 & 23.8 & 22.1 & 20.3 \\
\hline Europe & 57.8 & 59.9 & 61.8 & 63.5 & 65.9 \\
\hline Oceania & 77.7 & 83.4 & 89.0 & 94.8 & 100.5 \\
\hline
\end{tabular}

Source: Authors' projections, see main text for details.

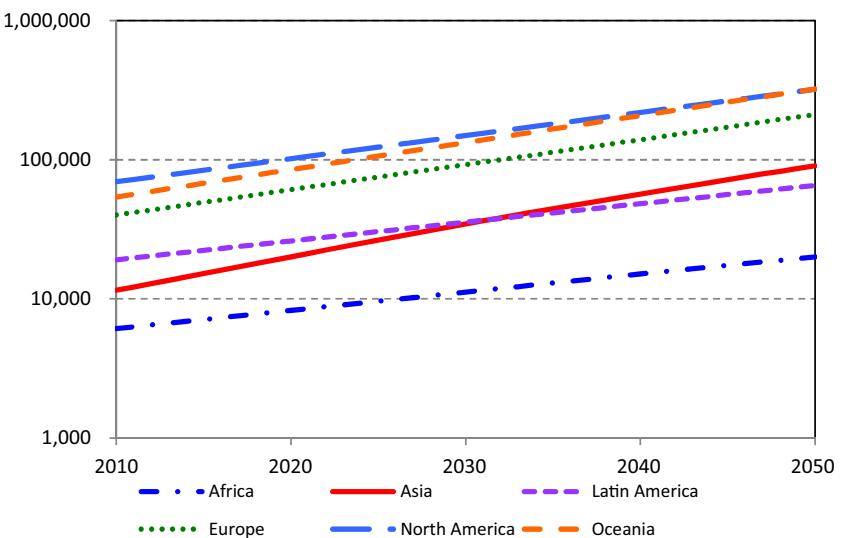

Figure 4. GDP per worker projections per continent; base scenario (log scale) 2010-50. Source: Authors' calculations.

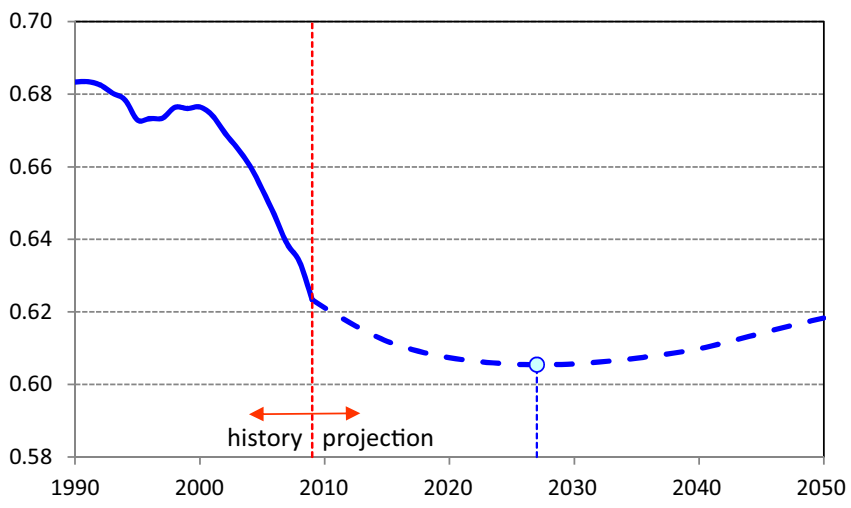

Figure 5. Global Gini coefficient; base scenario, 1990-2050. Source: Authors' calculations; The circle in 2027 indicates the minimum Gini value of 0.60543 . 
decrease in global inequality, in particular due to the Asianand subsequent Latin American crises of 1997 and 1998 which resulted in a short period of income divergence. From 2000 onward a clear decrease in global inequality is visible. The prediction, starting in 2010, suggests that the decline in global income inequality, which started at the end of the 1970s, comes to a halt around 2027 and then reverses to a process of rising income inequality.

By 2050 global income inequality is expected to have returned to levels similar to that of today. The Lorenz Curves shown in Figure 6 illustrate that most of the decrease in inequality in the period during 2000-27 can be attributed to the creation (or expansion) of a global middle income class, see also Ravallion (2010). Especially the third and the fourth quintiles command a larger share of total income in 2027 compared to 2000. The rise in inequality projected to occur during 2027-50 is clear from the Lorenz curves, but does not yet take us close to the 2000 level. The next paragraphs will delve deeper into the mechanics behind this central finding.

\section{(b) Income distributions}

The base scenario predicts another 15 years of income convergence after which a diverging trend reappears. To analyze the dynamics behind this development, a closer look at the data is required. One way of doing is, is by constructing a World Distribution of Income (WDI). The WDI is the result of a Kernel Density Function in which all 880 income groups ${ }^{6}$ are population-weighted and effectively integrated into one global income distribution. We follow Sala-i-Martin (2006) in using a kernel bandwidth $w=0.9 \times s d \times n^{1 / 5}$ where sd is the standard deviation of $\log$ income and $n$ is the number of observations.

Figure 7 has the income level (log scale) on the horizontal axis and millions of people on the vertical axis. The density function comprises of a hundred different points, each of which corresponds to a number of people and matching income level. The area under the lines is equal to the total world population in the respective years. The WDI allows for analyzing the relative income levels of different groups of people and incorporates both population and income growth.

Each consecutive WDI above is larger (a larger area under the graph) and shifted to the right in comparison to the one before. This corresponds with growing world population and rising income levels. Because of these two large-scale developments most other shifts are small in comparison and therefore

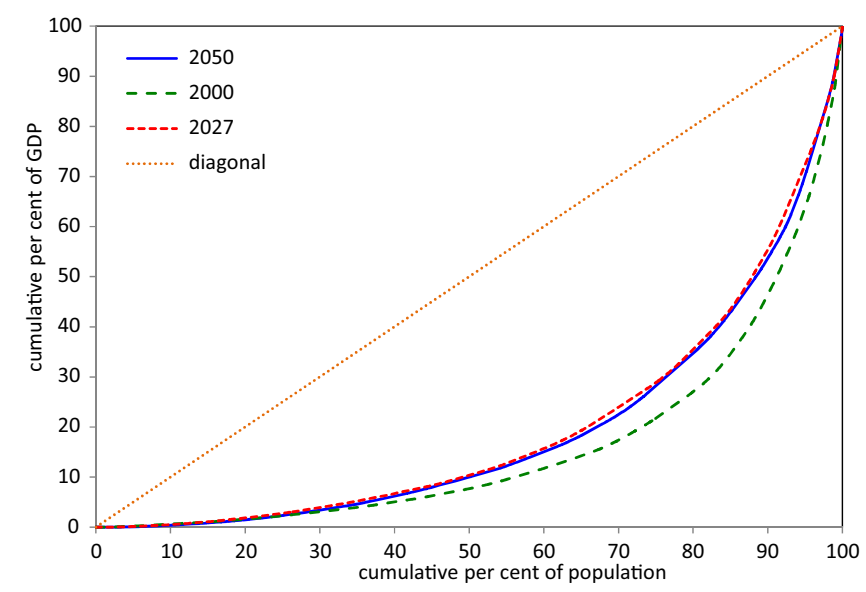

Figure 6. Global Lorenz curves; base scenario, 2000, 2027, and 2050. Source: Authors' calculations.

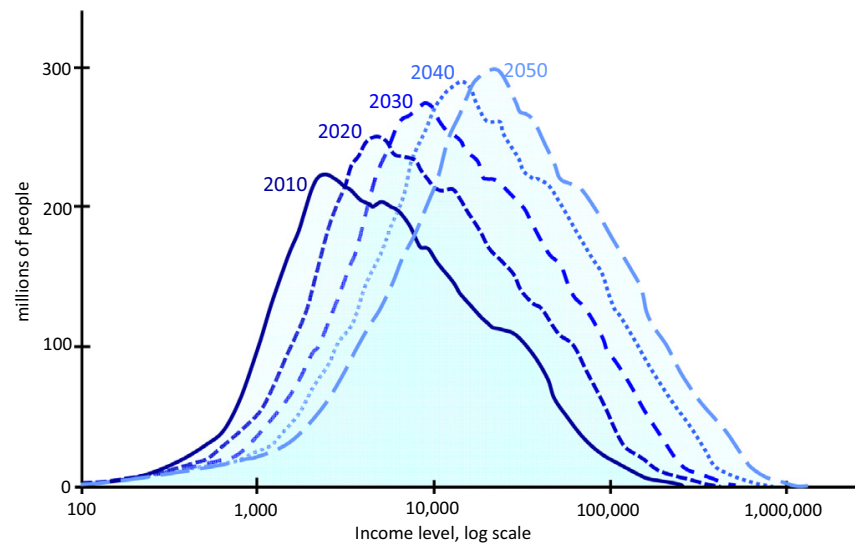

Figure 7. World distributions of income, 2010-50. Source: Authors' calculations.

hardly visible. Figure 8 takes this approach one step further and looks at different regions ${ }^{7}$ in relation to one another. Sub-Sahara Africa (SSA), South Asia (SA), East Asia (EA) and the OECD countries are each shown as individual distributions ${ }^{8}$ for 2010 and 2050.

This added detail provides a number of interesting insights with regard to the reversal of the income inequality trend depicted in Figure 5.

First: Considerable shifts are visible, both in individual distributions as well as in distributions in relation to each other. All distributions shift to the right, but South Asia and East Asia move relatively faster. A consequence of this is that East Asia has more overlap with the income distribution of the OECD countries in 2050 than it had in 2010. The same holds for South Asia.

Second: The continent distributions shift relative to each other. Some of these shifts result in an overall decrease of inequality and some result in an overall increase of inequality. With respect to South Asia and East Asia the situation is more complex. While these countries catch up to OECD countries, they simultaneously pull away from most other African and Asian countries (the latter are not shown in the graph). For example, China has over the past few decades grown faster than the OECD average. At the same time it outgrew most African countries resulting in diverging (from Africa) and converging (toward the OECD) trends at the same time. The net result for global income inequality depends on the relative size of the diverging and converging forces in relation to each other.

Third: The OECD countries and East Asia (mainly China) show a modest population growth. South Asia (India) and Sub Sahara Africa are projected to significantly increase in population. ${ }^{9}$ This impacts global inequality in at least two ways. First, a rapid increase in population is often associated with a higher youth dependency ratio and subsequent lower economic growth. Countries with an extremely high population growth are thus at risk to (economically) lag behind countries with a lower population growth. A similar observation can be made for very low population growth which results in a larger old age dependency ratio. ${ }^{10}$ Second, population size also directly influences inequality measures such as the Gini-coefficient. The bulk of low-income countries are situated in Sub Sahara Africa. As the population in Sub Sahara Africa grows more rapidly than in the rest of the world, the relative weight of the continent increases. Therefore, inequality would increase even if GDP per capita is assumed to stay the same in all countries over the entire period, as we explain in an alternative scenario in Section 5. 


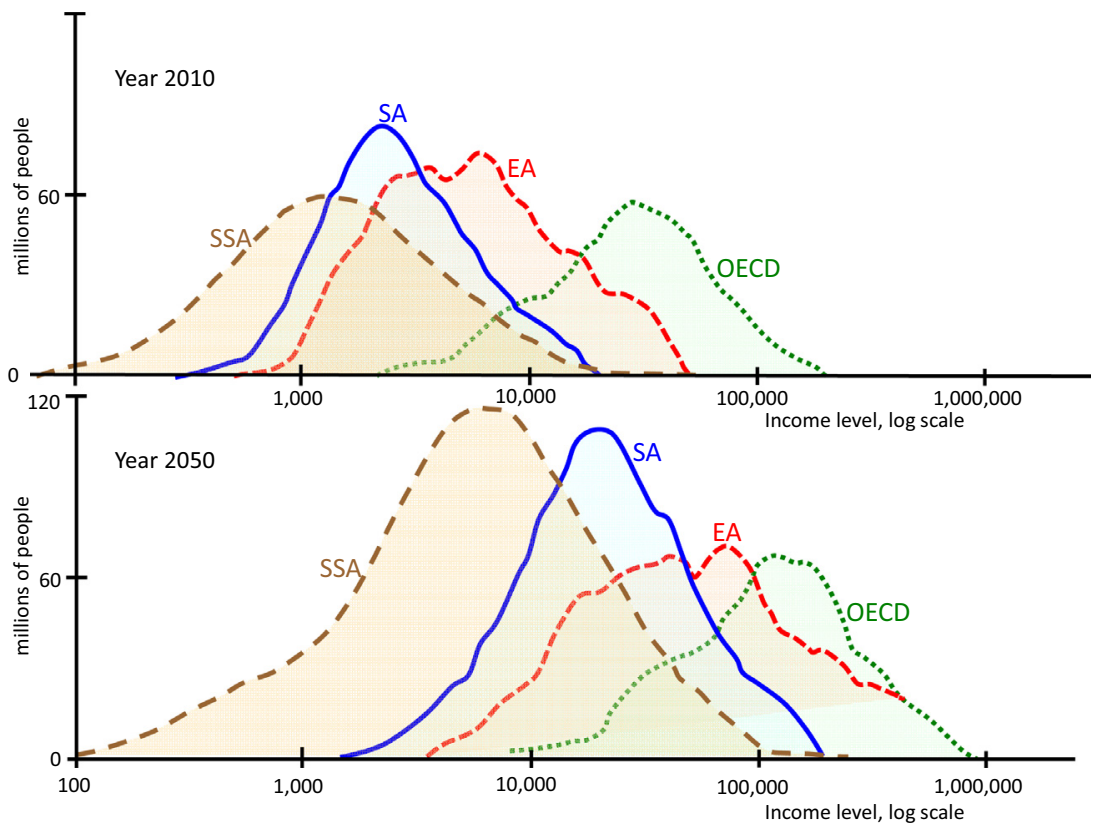

Figure 8. Regional distributions 2010-50. Source: Authors' calculations; $E A=$ East Asia, $S A=$ South Asia, SSA $=$ Sub Sahara Africa .

The projected reversal of the current trend of income convergence can thus be better understood by identifying a number of simultaneous developments. Projected growth in Asian countries can lead to income convergence as well as income divergence. In the past decades the converging force has been stronger, resulting in a net decrease of global income inequality. As income levels in Asian countries start to exceed the world average, the effect of declining income inequality diminishes while the diverging force resulting from pulling-away from a number African countries increases. In addition, demographic developments act as a separate diverging force. Not only the distance (difference in income level) but also the size of the relevant population matters when calculating inequality. A larger population in Sub Sahara Africa thus results in a higher global Gini-coefficient even without changes in income levels.

\section{(c) Poverty}

We briefly discussed studies on changes in poverty (absolute levels) and poverty rates (share of population in poverty) in Subsection 2(a). In general, as income per capita levels rise poverty rates decline, although poverty levels may still increase. Changes in within-country income inequality at the country level may of course frustrate the decline in poverty. Klasen (2008) and Ravallion (2014) provide a more detailed review of the ongoing debate regarding the relationship between growth, inequality, and poverty reduction. Since we keep this inequality constant in our base scenario (see the discussion in Section 6) the impact on poverty using any fixed poverty level, such as \$2 per day, is straightforward: poverty rates will decline. The more interesting question is then the distribution of poverty and poverty rates.

Figure 9 shows the results for the base scenario regarding poverty (panel a) and poverty rates (panel b) using the $\$ 2$ per day (2005 international dollars) poverty line. The poverty level fell enormously in Asia from 2000 to 2009 and is eradicated by 2025. Since 2003 the largest number of poor people live in Africa, where it declines slowly to about 170 million in 2050. There is also a small number of poor people in Latin America up to that point. In terms of poverty rates (panel b)
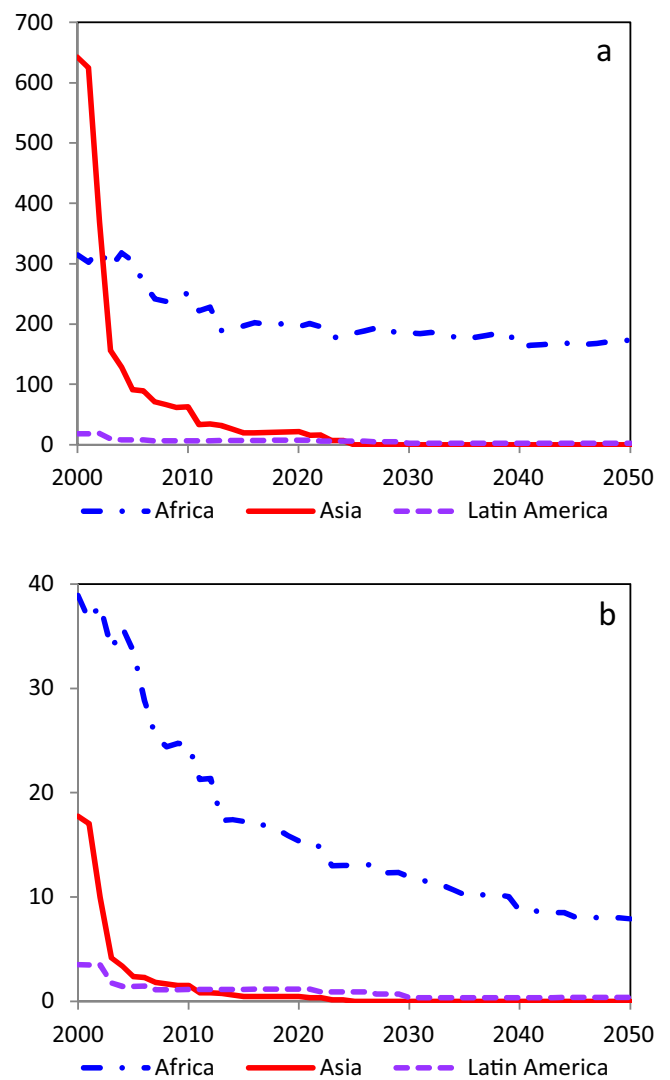

Figure 9. Poverty; people below $\$ 2$ per day poverty line, base scenario Panel a million of people; panel $b$ poverty rate (\%).

the decline is also substantial in Africa, from about $40 \%$ in 2000 to about $8 \%$ in 2050 .

In reality, the picture is, of course, not that simple. Poverty is a relative concept, which is why national poverty lines are substantially higher in advanced countries. If we, for example, use a dynamic poverty line of the number of people living 
below $10 \%$ of the world average income level (which is roughly equivalent to the $\$ 2$ per day poverty line in the year 2000), similar calculations as above would show that the poverty level will rise in Africa (its poverty rate will also rise slowly), and that poverty is not eradicated in Asia, Latin America, and Oceania (with poverty rates around $4 \%$ or more in 2050 ).

\section{ROBUSTNESS CHECKS}

Alternative scenario's and inequality measures confirm the conclusions drawn from the base scenario projection. Demographic projections are identified as contributing to income inequality divergence even when differences in economic growth between countries are ignored.

\section{(a) Alternative scenario's}

Section 4 has discussed a number of implications of the base scenario. Here a number of alternative scenario's will be introduced. These alternative scenarios provide additional insights as they allow us to separate the effects of economic growth and demographic developments. At the same time they are useful robustness checks for the base scenario. Three alternative scenarios are specified, namely:

- Zero Population growth. Stagnant population in all countries; GDP per worker projections as in the base scenario.

- Zero GDP per worker growth. Stagnant GDP in all countries; population demographics as in the base scenario.

- Continued GDP per worker growth. No reversal of GDP per worker projections to the continent mean, population demographics as in the base scenario.

The zero population growth and zero GDP per worker growth scenario's allow for analyzing the relative impact of demographic developments. The continued GDP per worker growth scenario signifies the difference between simply extrapolating 1990-2009 trends and the more eloquent method based on a gradual reversal of GDP per worker to the continent average that is used in the base scenario.

Figure 10 illustrates the impact of the various scenarios on global income inequality for the Gini coefficient. The zero population growth scenario allows us to focus on the impact of growth projections and the convergence - divergence forces touched upon in Subsection 4(b). Regarding global inequality, the zero population growth scenario starts to diverge from the base scenario essentially from 2030 onward. This indicates that the growth projection impact and the reversal from

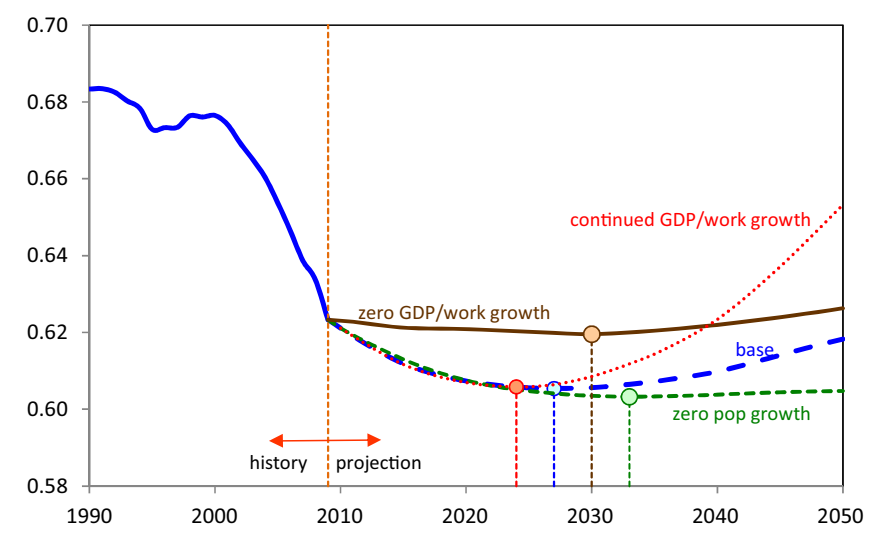

Figure 10. Global Gini coefficient, various scenarios. Source: Authors calculations; the circles indicate the timing and level of the minimum Gini value for the various scenarios, see Table 2. converging to diverging forces for East Asia and South Asia relative to the OECD on the one hand and Africa on the other hand is mostly noticeable in the long run. Evidently, what was a converging force in the past will cease to be so around 2030. This scenario also illustrates the diverging impact of the projected demographics; the base scenario with population growth results in higher inequality than the zero population growth scenario, essentially because of the rising importance (weight) of Sub Sahara Africa. Most importantly, however, our basic trend continues to hold: even without population growth global income inequality is projected to increase from 2033 onward.

The zero GDP per worker growth scenario allows us to focus attention on the demographic developments. As is evident from Figure 10, this is a rather extreme scenario where the developments of the past decade are abruptly transformed to an almost static development in global income inequality. This can be expected, of course, because the focus on demographic factors alone obviously leads only to a gradual change in inequality. As before, however, we see the same pattern: first a continued decline in global income inequality until 2030, followed by a rise in inequality afterward. It is reassuring for our base projections that the two main forces that play a role in determining future global income inequality, the growth projections and the demographic developments, both lead to the same first-decline-and-then-rise pattern. As illustrated by the base scenario, the interaction of these two forces reinforces these developments: the minimum is reached earlier and the changes in inequality are larger.

In light of the above, the results for the continued GDP per worker growth scenario can be readily explained. In this case the growth projections are sharpened which, in interacting with the demographic developments, further reinforces the pattern of the base scenario. The minimum income inequality is reached earlier (namely in 2024) and the changes in inequality are larger still.

\section{(b) Alternative inequality measures}

The discussion so far has been based on the Gini coefficient as a measure of global income inequality, partially based on the finding of Sen (1976) that the Gini can be seen as a distribution-free inequality index that represents the views on inequality of a society with very general distributional preferences. Alternative inequality measures are, of course, also available. They lead, in general, to the same overall picture: global income inequality first declines, then reaches a minimum and starts to increase again. This is illustrated in Table 1 for the Mean Log Deviation and three versions of the Generalized Entropy measure for all four scenario's discussed above.

Using the alternative measures, the base case switches from declining to increasing global income inequality about 10 years earlier. This effect is a bit stronger for the zero population growth case, where the switch occurs around 16 years earlier. In contrast, the other two scenarios, the zero GDP per worker growth case and the continued GDP per worker growth case, are hardly affected regarding the timing of the switch. In all cases, however, the same pattern is observed: first declining and ultimately rising global income inequality. Only the timing of the switch differs.

\section{CHANGES IN WITHIN-COUNTRY INEQUALITY}

Our discussion so far has ignored changes in within-country income inequality by using (and keeping constant) the most 
Table 2. Year of reaching minimum global income inequality

\begin{tabular}{|c|c|c|c|c|c|}
\hline Scenario & Gini & MLD & $\mathrm{GE}(0.25)$ & $\mathrm{GE}(0.5)$ & $\mathrm{GE}(0.75)$ \\
\hline Base & 2027 & 2016 & 2017 & 2017 & 2016 \\
\hline Zero GDP/worker growth & 2030 & 2035 & 2030 & 2030 & 2029 \\
\hline Zero population growth & 2033 & 2016 & 2017 & 2017 & 2016 \\
\hline Continued GDP/worker growth & 2024 & 2018 & 2023 & 2023 & 2025 \\
\hline
\end{tabular}

Source: Authors' calculations; MLD = Mean Log Deviation, GE = Generalized Entropy.

recently available quintile income distribution available. There are, of course, good reasons for this. First, there is no clear consensus regarding long-run changes in within-country income inequality. Sala-i-Martin (2006) finds a gradual increase of within-country inequality during 1970-2000. Yet he also states that this is mostly due to an increase of inequality in populous countries such as China and the United States. Second, when one looks at data for individual countries with many years of observations, such as Germany, Mexico, or Thailand, there are usually periods of rising within-country income inequality followed by periods of falling inequality. Third, within-country income inequality is affected by government policy and these policies may change in one way or another in a manner that is hard to predict. Fourth, long-run within-country inequality data are only available for a limited set of countries. Especially for many developing countries no comparable long-run data are available. For these reasons, analyzing the consequences of changes in within-country income inequality for the future trend of global income inequality is notoriously difficult, and perhaps best avoided.

Despite the above reservations, we do want to discuss the possibility of changes in within-country income inequality. To do this we use the latest version of the UNU-WIDER database on World Income Inequality (WIID3.b1, version September 2014), where we focus on the quintile distribution of the included studies if this is provided. Since our objective is to determine long-run trends in within-country income inequality we want to compare the first information for the country as a whole that is available for any country with the last (most recent) information. ${ }^{11}$ However, we also want to incorporate the quality of the observations, as indicated by the database in the four classes "not known", "low", "average", and "high". We therefore compare the first observation of average or high quality with the last observation of average or high quality. Only if observations of average or high quality were not available did we select low or not known quality (in that order). ${ }^{12}$ On the basis of these observations we calculated implied Gini coefficients to get an indication if within-country income inequality is rising or falling for the country under consideration.

Table 3 summarizes our findings for the 148 countries with more than one observation. ${ }^{13}$ Panel 2 a provides summary statistics on the year and Gini index of the first and last observation, as well as the change in the Gini index. The median first observation is in the year 1988 (average is 1985), ranging from a low of 1951 for India to a high of 2007 for West Bank and Gaza. The median last observation is in the year 2009 (average is 2007), ranging from a low of 1978 for Cuba to a high of 2012 for Bhutan, Latvia, Singapore, and Taiwan. The median difference between the first and last observation is thus 21 years (average is 22). The median Gini index for the first observation is 0.361 (average is 0.373 ) and for the last observation is 0.339 (average is 0.353 ). For the average country, therefore, the median Gini index has fallen by 0.019 or a modest $5 \%$ (the average by 0.020 , also $5 \%$ ) over a period of 21 years. Indeed, the Gini index fell for most countries (96 out of 148 or $65 \%$ ). The largest decline was in the Armenia from 1996 to 2011 (by 0.283 or $50 \%$ ). The largest increase was in Rwanda from 1985 to 2006 (by 0.202 or $76 \%$ ).

The information above does not necessarily imply that the declining within-country income inequality as summarized in Table 3 a translates into a decline in global income inequality if these trends continue in the future. This depends, among other things, on (i) regional differences and (ii) the trend for the most populous nations. Regarding (i), Table $3 \mathrm{~b}$ provides further information by detailing the changes in the Gini index for the six continents. We do not observe big differences between the continents regarding the change in the Gini index: the decline is small and holds for about $2 / 3$ rd of the countries. The only exception is North America, where the two countries involved (Canada and USA) both experienced an increase in within-country income inequality. Regarding (ii), Table $3 \mathrm{a}$ also provides a "population-weighted average Gini index", which thus takes the size of the population in a country into consideration. It shows that although there is a majority of countries where income inequality declined, this is almost perfectly compensated by the fact that income inequality increased for some populous nations, such as (in order of population size) in China (by 19\%), the USA (by 15\%), Indonesia (by $17 \%$ ), Bangladesh (by $21 \%$ ), and Nigeria (by $9 \%$ ). ${ }^{14}$ As a consequence, the population-weighted average Gini index is constant at 0.360 .

Ravallion (2014) finds that for the developing world as a whole within inequality has been falling slightly since 2000 . The 1990s, on the other hand, saw a slight increase. Our results, which predominantly reflect the 1990s and 2000s, are consistent with this observation. Ravallion further finds a small negative correlation between economic growth rates and inequality measures. Growth spells are nevertheless about as likely to coincide with rising as with falling inequality and no clear trend holding for the developing world as a whole can be identified. ${ }^{15}$

We abstain from projecting within-country inequality trends into the future for two reasons. First because conceptually there does not seem to be a good reason to expect current trends to necessarily continue into the future. Secondly, there are indications that within-country inequality has stabilized in recent years thus limiting the likely impact of within-country inequality on overall findings.

\section{CONCLUSIONS AND DISCUSSION}

We combined growth projections and demographic projections to analyze likely future trends in global income inequality. We analyze economic-demographic interactions by using GDP per worker for our growth projections and the UN's population dynamics on age structure to calculate GDP per capita for different income groups in each country on the basis of GDP per worker projections.

We find that the trend of decreasing global income inequality, which has been observed for the past several decades, will be reversed in the near future. Using the Gini coefficient, the lowest level of income inequality will be reached around 2027, after which global inequality will rise again. Using alter- 
Table 3. First and last quintile information and associated Gini coefficients

\begin{tabular}{|c|c|c|c|c|c|c|c|c|}
\hline \multicolumn{9}{|c|}{ 3a First and Last observation year and Gini coefficient } \\
\hline \multirow[b]{2}{*}{ Statistic } & & & \multicolumn{3}{|c|}{ First observation } & & Last observation & \multirow{2}{*}{$\begin{array}{c}\text { Change } \\
\text { Gini }^{*}\end{array}$} \\
\hline & & & Year & & Gini & Year & Gini & \\
\hline \multicolumn{2}{|l|}{ Average } & & 1985 & & 0.373 & 2007 & 0.353 & -0.020 \\
\hline \multicolumn{2}{|l|}{ Median } & & 1988 & & 0.361 & 2009 & 0.339 & -0.019 \\
\hline \multicolumn{2}{|l|}{ Minimum } & & 1951 & & 0.175 & 1978 & 0.186 & -0.283 \\
\hline \multicolumn{2}{|l|}{ Maximum } & & 2007 & & 0.651 & 2012 & 0.647 & 0.202 \\
\hline \multicolumn{2}{|l|}{ Standard deviation } & & 13.8 & & 0.100 & 5.9 & 0.083 & 0.074 \\
\hline \multicolumn{2}{|l|}{ Observations } & & 148 & & 148 & 148 & 148 & 148 \\
\hline \multicolumn{3}{|c|}{ Population weighted average Gini index } & & & 0.3598 & & 0.3597 & -0.000 \\
\hline \multicolumn{9}{|c|}{ 3b Change in Gini coefficients per Continent } \\
\hline Statistic & Asia & Africa & & Europe & & Latin America & Oceania & North America \\
\hline Average & -0.016 & -0.027 & & -0.007 & & -0.039 & -0.045 & 0.060 \\
\hline Median & -0.009 & -0.035 & & -0.018 & & -0.036 & -0.023 & 0.060 \\
\hline Minimum & -0.283 & -0.205 & & -0.110 & & -0.265 & -0.177 & 0.056 \\
\hline Maximum & 0.094 & 0.202 & & 0.122 & & 0.098 & 0.042 & 0.063 \\
\hline Standard deviation & 0.075 & 0.086 & & 0.062 & & 0.069 & 0.093 & 0.005 \\
\hline Observations & 41 & 35 & & 40 & & 26 & 4 & 2 \\
\hline Falling inequality & 23 & 25 & & 25 & & 20 & 3 & 0 \\
\hline Falling percent & 56 & 71 & & 63 & & 77 & 75 & 0 \\
\hline
\end{tabular}

Source: Authors' calculations based on UNU-WIDER World Income Inequality Database (WIID3.0b, Sep. 2014).

*The Gini index falls for 96 out of 148 countries $(65 \%)$ and rises for the other 52 countries.

\# The population-weighted average Gini index uses the total population in 2000 as weights (data from World Development Indicators; plus Maddison (2010) for Taiwan). The observations for no longer existing countries (Czechoslovakia, USSR, and Yugoslavia) are excluded from calculating the weighted average.

native inequality measures, the reversal may already start around 2017.

This trend reversal is the result of both economic and demographic developments, as well as the interaction between these two forces. High economic growth in a number of Asian countries makes that these countries simultaneously catch up with the advanced countries and pull away from other developing countries. This has long been a converging force but will soon result in increasing global income inequality. Demographic developments in Africa are a second diverging force. High projected population growth rates will slow economic development (especially compared with Asian countries with a "better" age structure) and will increase the "weight" of Africa in inequality measures. This force thus gains momentum over time.

Several alternative scenario's confirm and clarify the income inequality trend reversal. We identify projected demographic developments as a force of rising income inequality even when economic variables (GDP per worker) are held constant. Similarly, we identify projected economic developments ultimately also as a force of rising income inequality even when demographic variables (population) are held constant.

Within-country inequality is held constant in this analysis for two main reasons. First, because conceptually there does not seem to be a good reason to expect current trends to necessarily continue into the future. Second, our brief analysis of trends in within-country income inequality indicates that this inequality has stabilized in recent years, thus limiting the likely impact of within-country inequality on overall findings. 16

We take the two forces that lead to rising global income inequality, based on economic and demographic developments and the interaction between them, to be powerful forces which cannot easily be overturned. This raises the question whether we can avoid the imminent return to rising global income inequality. In essence we see only one way to do so. If populous nations like China and India manage to reduce their within-country income inequality levels, global income inequality may yet further decline despite the trend forces described above.

\section{NOTES}

\section{Hillebrand (2008) does provide estimates for the year 2015.}

2. The continent-wide growth rate in the period $1990-2009$ was $3.1 \%$ per worker in Africa and Latin America, 3.9\% in North America, $4.1 \%$ in Europe, $4.8 \%$ in Oceania, and $5.0 \%$ in Asia.

3. For the base scenario, for example, the minimum is ultimately imposed for one country (Zimbabwe) and the maximum for three countries (Kuwait, Qatar, and Luxembourg).

4. Using an estimation method such as Bhalla (2002) to smooth the Lorenz curve per country gives similar results with, obviously, somewhat lower Gini coefficients.
5. See the discussion in Subsection 4(b), however, on the importance and impact of differences in population growth within Asia.

6. Quintile data of 176 countries result in a total of 880 income groups with different income levels and population size.

7. Based on the geographic classifications used by the World Bank.

8. These distributions are each made up of 50 kernel data points.

9. Population growth during 2010-50 according to United Nations Population Department (2011): OECD from 1.23 to 1.40 billion, East Asia from 1.89 to 2.01 billion, South Asia from 1.63 to 2.31 billion and Sub Sahara Africa from 0.85 to 1.95 billion people. 
10. This is most relevant for OECD countries such as Germany and Japan.

11. We thus exclude studies covering only part of a country or only rural or urban areas. The only exception is for Germany, where we use the distribution of the West in 1968 and of Germany as a whole in 2011. This choice does not affect our findings below.

12. If our rules resulted in two or more estimates for the same year the highest quality estimate was chosen. In case of a tie we chose the most recently modified or updated one. In case of a further tie the first entry in the database was chosen.

13. There are 23 countries with just one observation, which are thus not included in Table 3. For these countries, the median observation is in 2003 (average in 1999) and the median Gini index is 0.408 (average is 0.420 ).
The within-country income inequality is thus substantially higher for these countries than for the countries included in Table 3 .

14. Income inequality on average declined by less in other populous countries, such as (in order of population size) in India (by 5\%), Brazil (by $10 \%$ ), Russia (by $7 \%$ ), Pakistan (by $12 \%$ ), and Mexico (by $22 \%$ ).

15. Latin America shows a sharp decline in within-country inequality whereas East Asia has seen an increase. Sub-Saharan Africa neither convincingly increases nor decreases its within-country inequality.

16. This does not mean that for decomposable income inequality measures the within-country inequality contribution is constant, because with different economic and population growth rates the decomposition weights change over time.

\section{REFERENCES}

Amsden, A. H. (2001). The rise of "the rest": Challenges to the west from late-industrializing economies. New York: Oxford University Press.

Bhalla, S. S. (2002). Imagine there's no country: Poverty, inequality, and growth in the era of globalization. Washington, DC: Peterson Institute.

Bloom, D. E., Canning, D., \& Malayney, P. N. (1999). Demographic change and economic growth in Asia. Working paper no. 15. Center for International Development, Harvard University.

Bloom, D. E., \& Sachs, J. (1998). Geography, demography, and economic growth in Africa. Brookings Papers on Economic Activity, 2, 207-273.

Bourguignon, F., \& Morrisson, C. (2002). The size distribution of income among world citizens: 1820-1990. American Economic Review, 92(4), $727-744$.

Brander, J. A., \& Dowrick, S. (1994). The role of fertility and population in economic growth. Journal of Population Economics, 7(1), 1-25.

Brat, D. A. (1995). A global Kuznets curve?. Kyklos, 48(1), 105-131.

Buiter, W., \& Rahbari, E. (2011). Global growth generators: Moving beyond the Brics. CEPR policy insight no. 55 .

Dadush, U., \& Stancil, B. (2010). The world order in 2050. Carnegie Endowment for International Peace Policy Outlook, February.

Dollar, D. (2005). Globalization, poverty, and inequality since 1980. The World Bank Research Observer, 20(2), 145-175.

Edward, P. (2006). Examining inequality: Who really benefits from global growth?. World Development, 34(10), 1667-1695.

Firebaugh, G. (2003). The new geography of global income inequality. Cambridge, MA: Harvard University Press.

Firebaugh, G., \& Goesling, B. (2004). Accounting for the recent decline in global income inequality. American Journal of Sociology, 110(2), 283-312.

Fouré, J., Bénassy-Quéré, A., \& Fantagné, L. (2010). The world economy in 2050: A tentative picture. Working paper 2010-27. CEPII.

Hawksworth, J., \& Cookson, G. (2008). The world in 2050: Beyond the BRICs: A broader look at emerging market growth prospects. London: PricewaterhouseCoopers.

Heston, A., Summers, R., \& Aten, B. (2011). Penn world table version 7.0 Center for International Comparisons of Production, Income and Prices at the University of Pennsylvania.

Hillebrand, E. (2008). The global distribution of income in 2050. World Development, 36(5), 727-740.

Hung, H.-F., \& Kucinskas, J. (2011). Globalization and global inequality: Assessing the impact of the rise of China and India, 1980-2005. American Journal of Sociology, 116(5), 1478-1513.

Jones, C. (1998). On the evolution of the world income distribution. Journal of Economic Perspectives, 11(3), 19-36.

Klasen, S. (2008). Economic growth and poverty reduction: Measurement issues using income and non-income indicators. World Development, $36(3), 420-445$.

Lindh, T., \& Malmberg, B. (2007). Demographically based global income forecasts up to the year 2050. International Journal of Forecasting, 23(4), 553-567.
Maddison, A. (2010). Statistics on world population, GDP and per capita GDP, 1-2008 AD. Available from: <http://www.ggdc.net/MADDISON/oriindex.htm>.

Milanovic, B., \& Yitzhaki, S. (2002). Decomposing world income distribution: Does the world have a middle class?. Review of Income and Wealth, 48(2), 155-178.

Park, D. (2001). Recent trends in the global distribution of income. Journal of Policy Modeling, 23(5), 497-501.

Poncet, S. (2006). The long term growth prospects of the world economy: Horizon 2050. Working paper no. 2006-16. CEPII.

Quah, D. (1993). Empirical cross-section dynamics in economic growth. European Economic Review, 37, 426-434.

Ravallion, M. (2001). Growth, inequality and poverty: Looking beyond averages. World Development, 29(11), 1803-1815.

Ravallion, M. (2010). The developing world's bulging (but vulnerable) middle class. World Development, 38(4), 445-454.

Ravallion, M. (2014). Income inequality in the developing world. Science, 344(6186), 851-855.

Sala-i-Martin, X. (2002). The disturbing "rise" of global income inequality. Working paper no. 8904. Cambridge MA: National Bureau of Economic Research.

Sala-i-Martin, X. (2006). The world distribution of income: Falling poverty and... convergence, period. The Quarterly Journal of Economics, 121(2), 351-397.

Schultz, T. P. (1998). Inequality in the distribution of personal income in the world: How it is changing and why. Journal of Population Economics, 11(3), 307-344.

Sen, A. (1976). Informational bases of alternative welfare approaches: Aggregation and income distribution. Journal of Public Economics, 3, $387-403$.

United Nations. (2008). UNU-WIDER world income inequality database, version $2.0 \mathrm{c}$.

United Nations. (2009). Department of Economic and Social Affairs, Population Division. Trends in international migrant stock: The 2008 revision.

United Nations. (2014). UNU-WIDER world income inequality database, version $3 . b 1$.

United Nations Population Department. (2011). World population prospects, the 2010 revision. Volume 1: Comprehensive tables. New York.

Williamson, J. G. (1998). Growth, distribution, and demography: Some lessons from history. Explorations in Economic History, 35(3), 241-271

Wilson, D., \& Purushothaman, R. (2003). Dreaming with BRICs: The path to 2050. Goldman Sachs, Global Economics Paper no. 99. 
APPENDIX A. COUNTRIES BY CONTINENT

\begin{tabular}{|c|c|c|c|}
\hline Africa & Uganda & Thailand & Latin America \\
\hline Algeria & Zambia & Turkey & Argentina \\
\hline Angola & Zimbabwe & Turkmenistan & Bahamas \\
\hline Benin & Tanzania & United Arab Emirates & Barbados \\
\hline Botswana & Togo & Uzbekistan & Belize \\
\hline Burkina Faso & Tunisia & Vietnam & Bolivia \\
\hline Burundi & & Yemen & Brazil \\
\hline Cameroon & Asia & & Chile \\
\hline Cape Verde & Afghanistan & Europe & Colombia \\
\hline Central African Republic & Armenia & Albania & Costa Rica \\
\hline Chad & Azerbaijan & Austria & Cuba \\
\hline Comoros & Bahrain & Belarus & Dominican Republic \\
\hline Congo, Dem. Rep. & Bangladesh & Belgium & Ecuador \\
\hline Congo, Republic of & Bhutan & Bosnia and Herzegovina & El Salvador \\
\hline Cote d'Ivoire & Brunei & Bulgaria & Grenada \\
\hline Djibouti & Cambodia & Croatia & Guatemala \\
\hline Egypt & China & Czech Republic & Guyana \\
\hline Equatorial Guinea & Cyprus & Denmark & Haiti \\
\hline Eritrea & Georgia & Estonia & Honduras \\
\hline Ethiopia & Hong Kong & Finland & Jamaica \\
\hline Gabon & India & France & Mexico \\
\hline Gambia, The & Indonesia & Germany & Nicaragua \\
\hline Ghana & Iran & Greece & Panama \\
\hline Guinea & Iraq & Hungary & Paraguay \\
\hline Guinea-Bissau & Israel & Iceland & Peru \\
\hline Kenya & Japan & Ireland & Puerto Rico \\
\hline Lesotho & Jordan & Italy & St. Lucia \\
\hline Liberia & Kazakhstan & Latvia & St.Vincent \& Grenadines \\
\hline Libya & Korea (Rep) & Lithuania & Suriname \\
\hline Madagascar & Kuwait & Luxembourg & Trinidad \&Tobago \\
\hline Malawi & Kyrgyzstan & Malta & Uruguay \\
\hline Mali & Laos & Montenegro & Venezuela \\
\hline Mauritania & Lebanon & Netherlands & \\
\hline Mauritius & Macao & Norway & Oceania \\
\hline Morocco & Malaysia & Poland & Australia \\
\hline Mozambique & Maldives & Portugal & Fiji \\
\hline Namibia & Mongolia & Romania & Micronesia, Fed. Sts. \\
\hline Niger & Nepal & Russia & New Zealand \\
\hline Nigeria & Oman & Slovak Republic & Papua New Guinea \\
\hline Rwanda & Pakistan & Slovenia & Samoa \\
\hline Sao Tome and Principe & Philippines & Spain & Solomon Islands \\
\hline Senegal & Qatar & Sweden & Tonga \\
\hline Sierra Leone & Saudi Arabia & Switzerland & Vanuatu \\
\hline Somalia & Singapore & Ukraine & \\
\hline South Africa & Sri Lanka & United Kingdom & North America \\
\hline Sudan & Syria & & Canada \\
\hline Swaziland & Tajikistan & & United States \\
\hline
\end{tabular}

